\title{
Evolving with the Times, the New National Toxic Substance Incidents Program
}

\author{
Mary Anne Duncan • Maureen F. Orr
}

Published online: 14 September 2010

(C) American College of Medical Toxicology 2010

\begin{abstract}
ATSDR's surveillance and registries branch has a new three-part program to gather data on toxic substance incidents, the National Toxic Substance Incidents Program (NTSIP). NTSIP includes state-based surveillance of releases, a national database of chemical incidents, and incident investigations after large releases. NTSIP replaces the Hazardous Substances Emergency Events Surveillance program. Through this more comprehensive program, ATSDR is collecting data that may be used to decrease the number and severity of chemical releases and enhance preparedness, so that the health effects of future incidents are minimized.
\end{abstract}

\section{Introduction}

During 1990-2009, the surveillance and registries branch, within ATSDR's Division of Health Studies, maintained cooperative agreements with state health departments to conduct surveillance and promote preparedness and prevention of toxic substance releases and associated public health impacts. Nineteen states collected data on acute hazardous substance releases through the Hazardous Substances Emergency Events Surveillance (HSEES) program [1]. The data included chemical(s) released, location of incident, factors associated with the release, and number of injuries/fatalities, among other information. Data collected on these releases were entered into a database maintained

\footnotetext{
M. A. Duncan · M. F. Orr $(\triangle)$

Agency for Toxic Substances and Disease Registry,

Division of Health Studies, Surveillance and Registries Branch,

4770 Buford Hwy NE, MS F-57,

Atlanta, GA 30341, USA

e-mail: morr@cdc.gov
}

by ATSDR. The data have been analyzed and used by the states for awareness, alerting, and targeted prevention activities. For example, ammonia incidents with nurse tanks in an agricultural state caused a substantial number of injuries; therefore, the health department targeted farmers with information promoting safe ammonia handling practices.

In January 2010, HSEES evolved into a new ATSDR program, the National Toxic Substance Incidents Program (NTSIP). NTSIP expands on the work done through HSEES. It is designed to be a partnership between ATSDR and multiple stakeholders, such as state environmental and health agencies, other government agencies, labor, academia, non-governmental organizations, and industry. NTSIP provides a comprehensive approach to toxic substance surveillance, prevention, and response. As with HSEES, data collected through this program can be used for preparedness training, targeted prevention activities, and identification of health effects of chemical exposures.

The objective of this article is to introduce NTSIP and describe its three components.

\section{State-Based Surveillance}

Currently seven-state health departments have cooperative agreements with ATSDR to participate in NTSIP. They are Louisiana, New York, North Carolina, Oregon, Tennessee, Utah, and Wisconsin. As in HSEES, participating state health departments collect detailed toxic substance incident data and enter it into a web-based system maintained by ATSDR. Through NTSIP, state health departments also collect information about the production, use, and transport of hazardous substance within their boundaries. Using geographic information systems (GIS), states map the movement and locations of hazardous substances to identify potential threats to public health, such as use or 
storage of large amounts of a highly hazardous substance adjacent to a school or nursing home.

Although prevention outreach was a part of the HSEES program, it has a much larger role in NTSIP. Participating health departments prioritize the vulnerabilities identified using GIS and target them for prevention outreach activities. They evaluate the use of hazardous substances within their boundaries and determine where hazard reduction principles, green chemistry, or inherently safer technologies can be applied, then meet with community and industry partners to promote use of these alternate substances or technologies. They also work to enhance preparedness and response capabilities within their states so that consequences of toxic substance releases can be minimized.

Data from the HSEES or new NTSIP databases is available for research through the ATSDR website [2].

\section{National Surveillance}

The national database of chemical incidents uses the Department of Transportation's (DOT) Hazmat Intelligence Portal to combine data from existing databases such as the National Response Center's Incident Reporting Information System [3] and the DOT's Hazardous Materials Information System [4] with the NTSIP state surveillance data. The national database is supplemented with information from news media. Other databases will be included as they become available.

The goal of this surveillance is to provide more detailed nation-wide information about toxic substance releases. The system's data can be used by federal, state, and local agencies, emergency responders, and researchers for preparedness planning. The national database includes chemical incidents and injury estimates for the entire USA and more detailed data trends for NTSIP states.

\section{Incident Investigations}

The third component of NTSIP is rapid public health assessments after large-scale chemical incidents through the Assessment of Chemical Exposures (ACE) program. Through ACE, ATSDR provides assistance to state and local health agencies to investigate large-scale incidents in which at least 100 persons are exposed to a toxic substance at levels that could produce acute health effects. The ATSDR team can deploy within 1-2 days of receiving a request for assistance from a state health department. The team will assist in registering persons exposed and characterizing subsequent acute health effects. The ACE team is multi-disciplinary and may include personnel from the following fields: epidemiology, medicine, toxicology, statistics, veterinary medicine, environmental health, indus- trial hygiene, GIS, and data management. The ACE questionnaires and consent forms are adaptable and can be tailored to meet the needs of each incident.

In some incidents, ATSDR's Rapid Response Registry (RRR) form [5] is used to capture contact information of exposed individuals soon after the incident. Individuals are contacted later for an in-depth interview using the ACE survey. The RRR is a quick survey form containing 38 questions that captures contact information for the exposed person and two friends or relatives, exposure information, exposure-related health effects, health insurance information, and two event-specific questions. During ACE investigations, the short version of the RRR form containing the four questions needed to establish an official registry (name, sex, home address, and phone numbers) may also be used.

In most investigations, the ACE team attempts to interview all potentially exposed persons. In very large incidents, a sample of exposed individuals may be interviewed. Participants in the ACE survey can include community members, local business employees, responders, hospital personnel, and anyone else identified as being in the area at the time of potential exposure. The survey captures exposure history; symptoms experienced; health services use related to the incident; needs resulting from the chemical release; demographic information; medical history; and unrelated potential chemical exposures from jobs, lifestyle, habits, and hobbies. The team will also gather information on how people were notified about the event and what were the most effective and accurate methods of communication. Questions may also be asked about the impact of the incident on pets and any veterinary care required.

If there is a laboratory test that can be used to determine if exposure to the chemical has occurred, the ACE investigation may include collecting blood or urine and facilitating analysis at either the state public health laboratory or the CDC's National Center for Environmental Health laboratory. If environmental sampling is needed, ATSDR may make arrangements to have testing done on air, water, soil, or surface samples. Environmental sampling may also be done in homes or other buildings when sheltering-in-place has been ordered to evaluate the effectiveness of this exposure reduction tactic.

A pilot ACE investigation was conducted in June, 2010 in California after a tank containing chlorine was pierced at a metal recycling facility. The ACE team collaborated with the California Department of Public Health Division of Environmental and Occupational Disease Control Emergency Planning and Preparedness (EPP) Team to perform a rapid assessment. Persons exposed to the chlorine were interviewed using the ACE survey. The survey collected additional data on health effects and treatment required 
through medical chart reviews at the treating hospitals. Emergency responders and local environmental health officials were also interviewed to gain a better understanding of the incident and response. As a result of the investigation, the EPP team has created a Chemical Release Alert to distribute to metal recycling facilities advising them of the danger posed by closed tanks received for recycling. Unmet medical needs resulting from the chlorine exposure were identified during the interviews and referrals were made by the local health department for sources of care. A manuscript detailing the health effects and recommendations is being prepared.

\section{Summary}

ATSDR's Division of Health Studies is developing a body of knowledge about acute health effects from toxic substance releases, working to decrease the number and severity of releases, and enhancing preparedness for chemical incidents through the NTSIP program. The data collected are available to toxicologists and other health professionals for use in understanding causes and results of chemical incidents in the USA. Additional information about the program and how to request data is located at the NTSIP website [6].

\section{References}

1. Agency for Toxic Substances and Disease Registry. Hazardous Substances Emergency Events Surveillance. Historic website. Available at: http://www.atsdr.cdc.gov/HS/HSEES/index.html. Accessed 8/6/2010

2. Agency for Toxic Substances and Disease Registry. Hazardous Substances Emergency Events Surveillance public use data file. Available at: http://www.atsdr.cdc.gov/hs/hsees/Public_Use_File. html. Accessed 8/6/2010.

3. National Response Center. NRC Background website. Available at: http://www.nrc.uscg.mil/nrcback.html. Accessed 8/6/2010

4. US Department of Transportation. Pipeline and Hazardous Materials Safety Administration. Incident reporting website. Available at: http:// www.phmsa.dot.gov/incident-report. Accessed 8/6/2010

5. Agency for toxic Substances and Disease Registry. Rapid response registry website. Available at: https://www.rapidresponseregistry. org/. Accessed 8/6/2010

6. Agency for Toxic substances and Disease Registry. National Toxic Substance Incidents Program website. Available at: http://www. atsdr.cdc.gov/ntsip/. Accessed 8/6/2010 